\title{
O direito à saúde no Brasil - uma análise sobre o exercício desse direito no contexto de pandemia da Covid-19
}

\author{
The right to health in Brazil - an analysis on the exercise of this right \\ in Covid-19's pandemic context
}

RAQUEL TORCANI CARMONA

Pontificia Universidade Católica de São Paulo-PUCSP

RESUMo Este artigo tem como meta analisar o exercício do direito à saúde garantido constitucionalmente a todos aqueles que se encontrarem, em caráter temporário ou definitivo, em território brasileiro sob a perspectiva da pandemia oriunda do contágio pelo coronavírus. Nesse contexto, é possível observar que o Sistema Único de Saúde brasileiro, mesmo com tantas deficiências e problemas, foi de fundamental importância para o combate à doença. Novos caminhos e soluções devem ser implementados, mas é importante também conhecer os aspectos positivos para que todos tenham ânimo em prosseguir na busca pelo aperfeiçoamento do sistema e sua ampliação.

Palavras-chave: Direitos e garantias fundamentais. Saúde. Direitos sociais. CoVID-19. CORONAVÍrus.

\begin{abstract}
This article aims to analyze the exercise of the right to health constitutionally guaranteed to all those who are, on a temporary or permanent basis, in Brazilian territory from the perspective of the pandemic resulting from contagion by the coronavirus. In this context, it is possible to observe that the Brazilian Unified Health System, even with so many deficiencies and problems, was of fundamental importance to fight the disease. New paths and solutions must be implemented, but it is also important to know the positive aspects so that everyone has the courage to continue in the search for the improvement of the system and its expansion.
\end{abstract}

KeyWords: Fundamental Rights and guarantees. Health. Social Rights. Covid-19. CORONAVÍrus.

\section{INTRODUÇÃO}

Certos fatos, em virtude de sua grande importância ou consequências que provocam, são destacados e servem como referencial para marcar determinadas épocas da humanidade 
para a melhor compreensão do contexto cultural, socioeconômico ou político da sociedade ou de um povo no tempo e no espaço.

Com a finalidade de ilustrar tal raciocínio, apontamos o fato de os historiadores, antropólogos e arqueólogos terem organizado a Era Pré-histórica em três períodos distintos, segundo o método de manufatura de ferramentas, utensílios e armas da época. Estabeleceu-se, assim, a Idade da Pedra, ou período neolítico (6000 a.C. a 2500 a.C.), seguida da Idade do Bronze (Oriente Médio, 2300 a.C.) com o desenvolvimento de uma liga metálica, resultantes da combinação do cobre (descoberto em torno de 6500 a.C.) com o estanho, e finalmente a Idade do Ferro (de 1200 a.C. a 550 a.C.) que fez nascer a metalurgia do ferro, apesar de que os indícios de utilização do ferro sejam de 3200 a.C.

A aurora do século XXI, mais precisamente o início da segunda década (2020), ficará marcada pela disseminação do coronavírus SARS-CoV-2, micro-organismo que provocou a pandemia da Covid-19 no mundo inteiro, de forma bastante democrática e indiscriminada. A exemplo do que aconteceu no início do século XX, com a disseminação da gripe espanhola, em que milhares de pessoas morreram, inclusive o presidente da República reeleito para o seu segundo mandato, Francisco de Paula Rodrigues Alves. ${ }^{1}$

Os coronavírus são integrantes de uma grande família de vírus que podem causar doenças em animais ou humanos. Em humanos, sabe-se que vários coronavírus ocasionam infecções respiratórias que variam do resfriado comum a doenças mais graves, como a Síndrome Respiratória do Oriente Médio (MERS) e a Síndrome Respiratória Aguda Grave (SARS). O tipo descoberto mais recentemente causa a doença denominada Covid-19, moléstia infecciosa cujo causador era desconhecido até ocorrer o grande surto na cidade de Wuhan, na China, durante o mês de dezembro de 2019.

A Organização Mundial da Saúde-OMS anunciou que a proliferação da Covid-19 atingiu o nível de pandemia no início de 2020, fenômeno que acontece quando uma epidemia se espalha por vários países ou continentes, afetando uma quantidade incontável de pessoas. A maioria dos casos iniciais ocorreu na China, mas outros países, inclusive Coreia do Sul, Irã e Itália, também tiveram uma progressão significativa da doença.

O referido vírus se espalhou rapidamente e em pouco tempo alcançou o continente americano, transpassando inúmeras fronteiras, desembarcando inclusive ao Brasil. As autoridades de saúde, no princípio, recomendavam que as pessoas permanecessem restritas aos limites geográficos de suas residências o máximo possível, incluindo limitar deslocamento para o trabalho e aconselhando às escolas e aos pais optar pelo acompanhamento escolar em casa, com o intuito de evitar o avanço viral. Mas logo sobreveio a necessidade de imposição de medidas restritivas mais severas pelos governos de todas as nações.

A pandemia que acometeu severamente o Brasil notabilizou as desigualdades sociais acentuando-as fortemente, também tornou ainda mais evidente as mazelas enfrentadas pela parcela mais vulnerável da população, que segue ignorada.

Elegeu-se duas vezes presidente da República, cumprindo integralmente o primeiro mandato (1902 a 1906), mas morreu antes de assumir o segundo mandato (que deveria se estender de 1918 a 1922). 


\section{A COVID-19 SOb UMA PERSPECTIVA MAIS AMPLA}

O avanço viral da Covid-19 representou um duro golpe na vida de todas as pessoas, contabilizando altos índices de contaminação e mortes. No Brasil, logo no início do surto, quando o vírus começou a se alastrar pelo continente europeu, mesmo não havendo qualquer caso registrado oficialmente, o Poder Executivo brasileiro, representado pelo Ministério da Saúde, publicou a Portaria nº 188-20-MS, de 3 de fevereiro de 2020, declarando Emergência em Saúde Pública de Importância Nacional (ESPIN) em decorrência da infecção humana pelo coronavírus (2019-nCoV), até então, se tratava apenas de perigo iminente de contágio e propagação do vírus (BRASIL, 2020).

Em virtude do fato notório de aumento acelerado de casos confirmados da doença aliado ao alto índice de letalidade, o presidente da República, com aprovação do Congresso Nacional, declarou estado de calamidade pública. Dessa forma, o Decreto Legislativo $\mathrm{n}^{\mathrm{o}}$. 6 de 2020 (BRASIL,2020), reconheceu para fins do artigo 65 da Lei Complementar $\mathrm{n}^{\mathrm{o}}$. 1.010/2000 (Lei de Responsabilidade Fiscal), a superveniência do estado de calamidade pública. Essa providência é imprescindível para permitir que o Poder Executivo aumente os gastos e permaneça desobrigado de cumprir a meta fiscal anteriormente prevista, fundamentalmente no que se refere à disponibilização de recursos para Estados-membros e municípios, no enfrentamento da crise sanitária.

A legislação especial para a regulação da pandemia (que vem sendo alterada por medida provisória e regulada por atos administrativos) trouxe uma série de possibilidades de restrição de liberdade, ensejadas pelo incisivo exercício do poder de polícia, por exemplo, a restrição excepcional de circulação, o uso de máscara de proteção em locais públicos, proibição de eventos onde haja aglomeração de pessoas, fechamento de bares, lojas, restaurantes e comércio em geral etc. (CARVALHO FILHO, 2012, p. 63).

$\mathrm{Na}$ órbita da ordem jurídica global, há uma divisão relacionada ao espaço geográfico onde a norma impõe sua validade, trata-se do Direito Interno e o Direito Externo ou Internacional. O sistema normativo global reúne uma quantidade expressiva de países empenhados na elaboração e efetivação de tratados humanitários, demonstrando o alto grau de uniformidade de opinião no cenário internacional acerca de temas que põem à luz os direitos humanos.

Simultaneamente associado ao sistema normativo global estão os sistemas jurídicos internos de proteção, que perseguem a efetividade dos direitos humanos nos planos regionais, criando, dessa forma, uma rede integrada de proteção humanitária. Os sistemas globais e regionais não são dicotômicos, mas complementares, inspirados pelos valores e princípios da Declaração Universal, compõem o espectro instrumental de proteção dos direitos humanos no plano internacional. Nessa ótica, os diversos sistemas interagem em benefício dos indivíduos protegidos.

Ao acolher como ponto principal a ser considerado, o valor da primazia da pessoa humana, os mecanismos se complementam, somando-se ao sistema nacional de proteção a fim de proporcionar a maior efetividade possível na tutela e promoção de direitos fundamentais. Estes são a lógica e o conjunto de princípios próprios do Direito dos Direitos Humanos (PIOVESAN, 2019). 
O desenvolvimento do Direito Internacional dos Direitos Humanos tem início a partir da Declaração Universal de 1948, mediante a criação de inúmeros instrumentos internacionais de proteção. A Declaração de 1948 oferece razões e valores, assim como unidade valorativa a esse campo do Direito, enfatizando a universalidade, indivisibilidade e interdependência dos direitos humanos.

No que se refere à questão da Covid-19, a robusta mobilização de alcance mundial estava ancorada sob a perspectiva dos direitos humanos que já se acomodou aos mecanismos de proteção internos e supra estatais.

À medida que a Covid-19 se espalha pelo mundo, com agressivo alcance de letalidade, quase nenhuma comunidade permaneceu intocada, fator acentuado pela evolução rápida da doença, levando os pacientes a óbito de forma muito ligeira.

Estão sendo tomadas medidas drásticas e urgentes, entretanto é necessário impor maior esforço para entrincheirar a proliferação da Covid-19, e de maneira simultânea agir em outras frentes, por exemplo, identificando infecções e cuidando dos doentes com moléstias preexistentes para evitar a morte, assim como a redução dos transtornos sociais e econômicos

O espírito colaborativo internacional e o compartilhamento de informações em todas as dimensões serão particularmente cruciais em países e regiões onde o sistema de saúde pública e a infraestrutura de assistência não se mostram adequados, e onde a moléstia ainda não alcançou o pico de impacto, e as condições sociais, econômicas e culturais indicam extrema vulnerabilidade à expansão do vírus e capacidade de resposta deficiente. Isso é, particularmente, verdadeiro para comunidades fixadas em regiões subdesenvolvidas ou em desenvolvimento, incluindo África, Ásia, e continente americano, bem como, localidades de grandes conglomerados urbanos.

Igualmente urgente é entender, projetar-se e nos prepararmos para os diversos aspectos do impacto provocado pela pandemia na economia e no atendimento de necessidades humanas iminentes. As entidades bilaterais de amparo ao desenvolvimento, e os bancos internacionais são fundamentais, assim como as fundações privadas que desempenham papel importante em cenários de crise internacional. Nesse aspecto, a Organização Mundial da Saúde - OMS ganhou protagonismo e se notabiliza pela grande relevância que se apresenta, necessitando do forte apoio e cooperação de todos os membros integrantes da comunidade mundial.

\section{A garantia de efetivação do direito à saúde prevista na Constitui- ÇÃo Federal de 1988}

Norberto Bobbio (1992, p. 32) afirmava que na condição de reivindicações morais, os direitos humanos nascem quando devem e podem nascer, não nascem todos de uma vez, nem de uma vez por todas. Para Hannah Arendt (1989), há certa tensão social na qual os menos favorecidos experimentam a negação de direitos fundamentais imposta pelos mais fortes, forjando o surgimento de regimes totalitários. Nessa linha de raciocínio, os direitos humanos não são dados gratuitamente, mas sim construídos, uma invenção humana, em constante processo de construção e reconstrução (PIOVESAN, 2019). 
Na visão de Hannah Arendt (1989), o totalitarismo é um modo de opressão política muito peculiar, que na sua essência se diferencia de outras formas de opressão. O indivíduo, quando excluído da teia das relações humanas, fica desprovido de dignidade humana, em outras palavras, ocorre a desumanização do sujeito.

A proteção constitucional de um direito assegura ao indivíduo o pleno exercício desse mesmo direito, pois busca blindá-lo de toda e qualquer possibilidade de ver-se negado.

A partir da Constituição Federal de 1988, a prestação de serviços públicos relativos à saúde foi estendida a todos os brasileiros e estrangeiros residentes no país, eliminando a restrição até então existente de assistência a determinados grupos. O apogeu do movimento sanitarista, extremamente festejado foi a Assembleia constituinte, pelo qual alcançou-se a criação do Sistema Único de Saúde. O fato de a prestação de serviços públicos de saúde não estar mais restrita aos trabalhadores do mercado de trabalho formal, sendo estendida a todos os brasileiros, independentemente de contribuição ou de qualquer vínculo empregatício, significou uma vitória gigantesca na luta pelos direitos humanos.

Surpreendentemente, até o advento da Carta Política de 1988, nenhum texto constitucional fazia referência expressa à saúde como interesse público basilar do pacto social, curiosamente só foi positivada no Brasil depois de 40 anos da Declaração de Direitos Humanos.

Complementando, o legislador constituinte de 1988 possibilitou mais uma importante evolução, ao consolidar a saúde como um direito de todos e dever do Estado, assegurou, ainda, o acesso universal e igualitário às práticas e serviços para sua melhoria, proteção e recuperação.

Segundo Germano Schwartz, tecendo considerações sobre o tema, afirma que:

[...] a valorização do direito à saúde se deve ao fato desse ser essencialmente um direito fundamental do homem, considerando-se que a saúde é "um dos principais componentes da vida, seja como pressuposto indispensável para sua existência, seja como elemento agregado à sua qualidade. Assim, a saúde se conecta ao direito à vida" (SCHWARTZ, 2001, p. 52).

De fato, a saúde é componente da vida, estando intimamente vinculada à dignidade da pessoa humana. Dessa forma, pode-se dizer que o direito à vida e à saúde são consequências da dignidade humana. Além disso, deve-se ter claro que o direito à saúde é direito à vida, pois a inexistência de um leva, inevitavelmente, ao fim da outra (PARANHOS, 2007, p. 156).

Perspectivas sobre o sistema único de saúde no Brasil

A alocação de recursos públicos, sempre tão escassos, deve ter em perspectiva a preservação do mínimo existencial, de maneira a conferir real efetividade às normas positivadas na própria norma constitucional. O Poder Público viola a Constituição Federal quando não obedece, totalmente ou em parte, o cumprimento do dever de executar políticas públicas fixadas no texto constitucional, pois a Constituição Federal tem por base 
a necessidade de uma ordem normativa inquebrantável, desenvolvida para efetivar e dar maior garantia ao tecido constitucional.

A ideia de mínimo existencial se traduz pelo conjunto de condições materiais essenciais e elementares cuja observância é pressuposto da dignidade para qualquer indivíduo. Uma espécie de linha limítrofe, determinando que se alguém estiver vivendo abaixo daquela linha, o comando constitucional estará sendo desrespeitado.

Ana Paula de Barcellos procura delimitar o conteúdo do mínimo existencial, segundo a realidade brasileira. De acordo com sua convicção, deve-se ter como certeza a garantia do minimamente exigível, direito à saúde, educação, assistência aos desamparados e acesso à Justiça (BARCELLOS, 2019). Nessa perspectiva, a garantia da integridade individual fica preservada na medida em que as necessidades forem atendidas para que a pessoa alcance a satisfação que está posta em níveis hierárquicos (necessidades fisiológicas, de segurança, relacionamentos, estima, cognitivas, estéticas, autorrealização e transcendência).

A indiferença do Estado pode ser interpretada como descaso ou desrespeito à norma constitucional, evidenciando prática de atitude juridicamente deplorável, autorizando a responsabilização do ente público. A omissão do Estado obriga à reparação pelos eventuais danos causados em razão de sua negligência, onerando, ainda mais, o erário público, já com recursos tão precários (PEDREIRA, 2016). Cabe aos indivíduos, sujeitos de direito e destinatários dos recursos públicos exigir a concretização das políticas públicas em favor dos direitos sociais.

A saúde é um serviço de grande importância e de interesse geral, pois é indispensável para a preservação da vida, por isso a Carta Política de 1988, no artigo 198, inciso II (BRASIL, 1988), determinou que as ações e serviços relativos à saúde deveriam ter atendimento integral, privilegiando-se as práticas preventivas, sem prejudicar os serviços assistenciais.

Ao lado da obrigação do Estado de manter o pleno funcionamento do sistema de saúde pública, está o dever de criar e implementar políticas públicas de redução do risco de doenças, ou seja, ostentar uma conduta preventiva, por meio de campanhas educativas, de vigilância sanitária, de desenvolvimento de recursos humanos, alimentação saudável, construção e manutenção de hospitais e os serviços correspondentes, centros ambulatoriais e postos de saúde etc.

Importante também observar, a questão do fornecimento gratuito de medicamentos para a recuperação ou para a redução das sequelas causadas pelas mais diversas razões, também merece ser observado. Muito embora não exista previsão constitucional expressa acerca da distribuição gratuita de medicamentos pelo Poder Público, não há dúvidas de que a obrigatoriedade de atender tal direito é um desdobramento do direito à saúde, convertendo-se em um legítimo direito social prestacional. Assim, tal prerrogativa exige uma destinação, distribuição e redistribuição, possuindo claramente uma dimensão econômica.

Segundo análise realizada e constante de relatório do Instituto de Pesquisas Econômicas Aplicadas 'IPEA, e de acordo com a definição de seguridade social, pautada na Convenção $n^{\circ}$. 102 da Organização Internacional do Trabalho - OIT, o sitema jurídico brasileiro reestruturado apartir de 1988 e mantido até hoje, além daquela conceito, outros princípios-chave, nos termos do artigo 194 que devem orientar toda a política de Seguridade Social, na Previdência, na Assistência Social e na Saúde, quais sejam: 
a) universalidade da cobertura e atendimento;

b) uniformidade e equivalência dos benefícios rurais e urbanos;

c) seletividade e distributividade na prestação de serviços;

d) irredutibilidade no valor dos benefícios;

e) diversidade da base de financiamento estruturada em orçamento da Seguridade Social (autônomo);

f) equidade na forma de participação no custeio; e

g) caráter democrático dos seus subsistemas (previdência, saúde e assistência).

Ressalte-se que a política de combate ao desemprego, sob a forma de benefício em pecúnia (seguro-desemprego), também foi inscrita no texto constitucional como parte da política previdenciária, cuja finalidade é prover garantia financeira temporariamente ao trabalhador desempregado e dispensado sem justo motivo, mesmo que de forma indireta, e ao obreiro resgatado de regime de trabalho forçado ou condição equivalente a regime escravo.

Nunca é demais relembrar a imensa e positiva inovação trazida pela Constituição Federal de 1988 que foi o benefício da prestação continuada (BPC), cujo objetivo assistencial assegurou a dignidade de pessoas em situação de miserabilidade, o impacto dessa medida foi de enorme expressão em diversas dimensões, um desses impactos foi a redistribuição de renda e a redução, ainda que tímida, da desigualdade.

A promulgação de uma Constituição Federal, cuja natureza social não encontra precedentes em nenhum instrumento jurídico brasileiro anterior a ela, por sua generosidade democrática foi reconhecida como "Constituição Cidadã".

Dessa forma, graças ao arcabouço legal dado pela Constituição, que foi fundamental para a inserção da política pública de assistência social, o princípio contributivo passou a caminhar paralelamente com o princípio de universalidade não contributiva, que atualmente orienta muitas das ações da Seguridade Social.

Tais anseios foram alimentados ao longo do tempo e permeados pelas reinvindicações das massas populares, que buscaram incansavelmente melhores condições de vida, na medida em que reconheciam e lutavam pela concretização de seus direitos.

Não é possível esquecer também que a fragilidade democrática e as disputas políticas que nasceram com a promulgação da Constituição Federal de 1988 e perduram até os dias atuais impossibilitaram a consolidação do princípio de Seguridade como uma fórmula de proteção social de bases sólidas e unificadas, polarizando dois paradigmas antagônicos. De um lado, estão aqueles que lutam na defesa da Seguridade como base de um projeto de Estado Social; enquanto que de outro, encontravam-se os que consideram os comandos constitucionais um obstáculo ao equilíbrio das contas públicas (DELGADO, JACCOUD, NOGUEIRA, 2019).

Tal disputa comparece continuamente nos debates em torno das questões do financiamento e do tão propalado déficit da Previdência Social, de tal modo que o debate tende a obscurecer o significado do novo sistema de proteção social.

Isso significa dizer que a questão do déficit previdenciário cria uma espécie de cortina de fumaça impedindo que a real importância do sistema de proteção social (a seguridade) receba o devido reconhecimento de seu valor enquanto avanço no desenvolvimento social da nação. 
O artigo 165, §5 $5^{\circ}$, inciso III, da Constituição Federal de 1988, institui o orçamento da Seguridade Social, distinguindo-o do orçamento fiscal constante do inciso I, do mesmo artigo e parágrafo, nos seguintes termos:

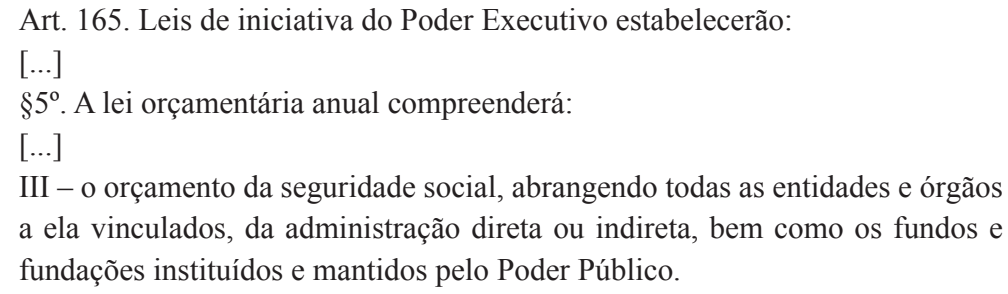

Contudo, é no Título que trata da ordem social abrangendo os artigos 194 até 204 (BRASIL, 1988), que estão incluídos todo o conteúdo reconhecido e vinculados aos direitos sociais, bem como, as respectivas obrigações fiscais pela Constituição Federal. No que tange à proteção social e às obrigações fiscais correspondentes, vale ressaltar que há pouca transparência na arrecadação e na aplicação dos recursos, assim como também não é clara a prestação de contas desse setor.

O Sistema de Seguridade Social é um conceito genérico, onde se englobam a previdência social, a assistência social e a saúde. Conceituado e com seus princípios definidos nos artigos 194 da Constituição Federal. No que diz respeito ao custeio, o artigo 195 aponta quais são as origens dos recursos que irão suportar a manutenção do complexo financiamento do sistema, cuja divisão pode ser feita de forma não-contributiva e forma contributiva.

A forma não contributiva não exige uma contribuição direta. Está embutida nos tributos exigidos pelo Estado de todos os cidadãos e que coloca o serviço à disposição de qualquer indivíduo que precise dele fazer uso, por exemplo, o sistema único de Saúde-SUS, que pelo princípio da universalidade não deve fazer distinção alguma entre seus usuários.

Por sua vez, a forma contributiva diz respeito à contribuição direta feita pelo segurado, na expectativa de receber um benefício futuro, por exemplo, a aposentadoria ou auxílio-doença.

O artigo $195, \S 4^{\circ}$. possibilita a criação de novas contribuições sociais, destinadas a garantir a manutenção ou a expansão da seguridade social. Contudo, deve-se observar o disposto no artigo 154 I (competência residual), dessa forma, pode-se concluir que:

i) as novas contribuições (sobre fontes diversas do art. 195) deverão ser criadas por lei complementar;

ii) devem ser não-cumulativas;

iii) podem ter a mesma base de cálculo e fato gerador de impostos discriminados na Constituição Federal, em face do entendimento do STF de que "não se aplica às contribuições sociais novas a segunda parte do inciso I do artigo 154 da Carta Magna, ou seja, que elas não devam ter fato gerador ou bases de cálculo próprios dos impostos discriminados na constituição" (RE 242.615, Rel. Min. Marco Aurélio e RE 231.096, 258.774; 252.242, Rel. Min. Moreira Alves).

Nessa perspectiva, revelam-se duas condições orientadoras: 
i) a diversidade das bases fiscais do financiamento - folha de salário, faturamento, lucro líquido etc., e

ii) o princípio da exclusividade das fontes, ao se eleger explicitamente as contribuições sociais e não os impostos como objeto de vinculação à Seguridade (DELGADO, JACCOUD, NOGUEIRA, 2019).

A doutrina identifica a natureza jurídica das contribuições sociais como tributos e apontam seis teorias que justificam esse pensamento, nas seguintes modalidades: a) teoria do prêmio de seguro, b) teoria do salário diferido, c) teoria do salário atual, d) teoria fiscal, e) teoria para-fiscal, e f) teoria da exação sui generis.

\section{A saúde no Brasil e a Pandemia da Covid-19}

O Sistema Único de Saúde (SUS), desde antes do seu nascedouro, nunca vivenciou um período de bonança. Forjado há 30 anos, em um momento histórico no qual as políticas do Estado Social perdiam espaço para o modelo neoliberal, o SUS vem experimentando mais um processo de fragilização oriundo da dinâmica do movimento do capital, em grande parte, comandado por forças aliadas ao capital portador de juros (capital financeiro).

Filiado à tradição das políticas públicas antes mesmo de sua concepção e integrante de um sistema de proteção social, denominado na Constituição de 1988 por seguridade social, o SUS sofre fortes críticas desde a sua existência. Tem sido vítima permanente da tensão entre a garantia da universalidade e a contenção de gastos. Essa tensão fica evidente quando se verifica a forma como têm sido conduzidas as políticas de gestão e, especificamente, aquelas referidas ao processo de avaliação em saúde.

Vivemos tempos desafiadores para o SUS e, especificamente, para a avaliação em saúde. São desafiadores, porque provocam questionamentos em relação ao processo de aperfeiçoamento da saúde pública. Desafios que são a expressão da fase atual do capitalismo, marcada pelo predomínio do capital financeiro que almeja obter lucro com base no capital fictício e parasitário, à medida que ocorre o declínio da lucratividade no setor produtivo.

Não se tem dúvidas de que o advento da pandemia colocou em evidência as desigualdades, as quais a população vulnerável está mais exposta. Há tempos, a situação no que diz respeito à área de saúde exige ações firmes e eficazes, a fim de reforçar a proteção social a esses grupos que são os mais impactados. Dessa forma, é preciso pensar em ações efetivas para impedir que a pandemia piore as condições de vida de milhões de brasileiros submetidos à vulnerabilidade.

Obviamente, sendo o Brasil um dos países mais desiguais do mundo, diante do quadro de pandemia, as diferenças de acesso dos cidadãos à proteção social, serviços públicos de saúde e trabalho que possibilite a geração de renda ficam ainda mais evidentes, a incidência da Covid-19 exacerbou desigualdades histórica. Isso porque a falta de efetividade dos serviços públicos básicos inacessíveis aos mais pobres é um problema de longa data em nosso país, e mesmo assim, nunca foi devidamente encarado com seriedade e firmeza pelo Estado. 
Algumas cidades, como São Paulo, que se notabiliza como um imenso centro urbano, são um verdadeiro celeiro para a proliferação de doenças, uma vez que as pessoas vivem apinhadas umas às outras, disputando espaço no transporte público, no mercado de trabalho, nas áreas de lazer etc. Pela mesma razão, São Paulo converteu-se no epicentro da pandemia no país, justamente por ser a unidade federativa mais numerosa, em termos populacionais.

Os problemas vão além da questão das desigualdades sociais, também há o problema da falta de informação segura sobre a evolução da pandemia ou mesmo, o número preciso de óbitos decorrentes dessa enfermidade. O Brasil tem dificuldades para realizar os testes de contágio, e ainda há subnotificações de infectados e óbitos em decorrência da Covid-19, o que impede ações de combate mais eficientes e precisas.

O contingente da população brasileira que mora em favelas, ou seja, cidadãos que vivem em condições precárias, espaços apertados com muitos moradores, mal ventilados e sem acesso ao saneamento básico torna o indivíduo em potencial vítima de várias moléstias. Além disso, possuem pouco ou nenhum acesso aos serviços de saúde e sem qualquer possibilidade de isolamento social ou meios de cultivar hábitos de higiene diários, circunstâncias que pioram muito, devido ao fechamento do comércio e ruas vazias, nas quais as pessoas em situação de rua acabam tendo menos recursos para se alimentar. Por tudo isso, o sistema de saúde já demonstra sinais de colapso, principalmente nos municípios menores, onde em alguns casos, sequer há leitos de UTI.

O caos na saúde pública brasileira agravado pela pandemia atinge não apenas a população, mas também os profissionais de saúde. A falta dos EPIs (equipamentos de proteção individual) tem gerado o aumento dos casos de contaminação entre médicos, enfermeiros e outros profissionais dessa área, como motoristas de ambulâncias, recepcionistas e seguranças de hospitais etc. A maioria da população depende do Sistema Único de Saúde-SUS, parte expressiva da população não tem plano de saúde particular e depende do serviço público.

Por outro viés, a falta de médicos também é um ponto importante quando tratamos dos problemas da saúde pública no Brasil. Segundo a Organização Mundial da Saúde, o ideal é que haja pelo menos 1 médico para cada mil habitantes. O Brasil supera tal proporção, contudo a distribuição pelo país é bastante desigual, havendo concentração de médicos nas regiões mais ricas e escassez nas localidades mais carentes, onde paradoxalmente esses médicos seriam mais úteis.

O Sistema Único de Saúde (SUS) foi uma grande conquista da população brasileira, sendo reconhecido como um dos maiores do mundo e usado como modelo em muitos outros países. O Ministério da Saúde foi criado em 1953, quando também começaram as primeiras conferências sobre saúde pública no Brasil. Assim, surgiu a ideia de criação de um sistema único de saúde, que pudesse atender a toda a população. Porém, apenas em 1986, na $8^{a}$ Conferência Nacional da Saúde, foi criado o documento que deu origem ao SUS. Depois, com a Constituição de 1988, foi estabelecido a saúde como um direito de todos os cidadãos, de acesso gratuito e como dever do Estado.

Ao analisar a saúde pública brasileira, podemos constatar um histórico de recursos escassos e mal geridos. Dessa maneira, os Estados e municípios possuem grandes responsabilidades em relação aos atendimentos, mas não recebem recursos suficientes para isso. 
A par disso, muitos municípios, principalmente os pequenos, têm dificuldade em gerenciar seus sistemas de atendimento. Como o município é responsável pela atenção básica, o que representa cerca de $85 \%$ dos atendimentos, as deficiências nesse nível comprometem a qualidade sanitária da população.

Por isso, medidas de austeridade, como a proposta na PEC 241, aprovada em 2016 que limita os gastos públicos em saúde - agravam ainda mais a situação da saúde pública no Brasil.

Garantir a qualidade e transparência do gasto público já era uma necessidade antiga e agora, com o agravamento da situação da saúde pública brasileira nesse contexto pandêmico, isso se torna ainda mais urgente. E uma das formas de se garantir esses recursos tão necessários é por meio de uma reforma tributária que reduza desigualdades. O modo como se cobra e se aplica os tributos pode aumentar ou reduzir desigualdades.

\section{CONSIDERAÇões FINAIS}

A situação atual é dramática, muito embora a humanidade tenha sido repetidamente acometida por epidemias provocadas por moléstias infecciosas e, tenha superado cada crise que se desdobrou a partir disso, continuaremos a enfrentar outras ameaças no futuro, de vírus gripais até as infecções resistentes às mais avançadas gerações de medicamentos. Serão necessários esforços concentrados na abordagem de conexões críticas entre a desenfreada degradação ambiental e os vetores de moléstias, a fim de se evitar futuros surtos de novos patógenos.

A tragédia da Covid-19 deve nos estimular a fortalecer drasticamente os esforços para prevenir e controlar doenças infecciosas, o que se faz com severos protocolos de higiene, habitações dignas e confortáveis e educação sanitária para que os grupos humanos melhorem seus estados de prontidão e aumentem a capacidade de resiliência às pestes e calamidades dessa natureza.

Ao Estado cabe em reconhecimento e prática de confiança global promover a coordenação e o alinhamento de processos regulatórios e de fabricação com padrões de qualidade necessários para ter sempre disponíveis recursos tecnológicos e equipamentos de proteção individual confiáveis, dispositivos de teste para diagnósticos precoces e capacidade de oferecer o devido tratamento médico.

À comunidade científica cabe empreender esforços colaborativos para realizar a rápida análise, e ministrar o tratamento imediato, no entanto sempre se baseando em evidências ou programas de combate que surgem na medida em que a pandemia global se movimenta.

O intercâmbio de informações entre a comunidade internacional deve ser veloz, preciso e transparente sobre o desenvolvimento da epidemiologia dessa patologia viral, incluindo informações como padrões de transmissão, período de incubação e letalidade, bem como, eficácia e utilização de métodos de intervenção eficazes.

No que diz respeito ao setor econômico, a atual fase do capitalismo é marcada por uma crise que atinge profundamente o setor em uma perspectiva global. As soluções escolhidas para amenizar os seus efeitos envolvem a adoção, pelas políticas austeras, de enérgi- 
cas reduções no gasto público, especialmente no gasto relacionado com as políticas sociais, impactando a saúde e, por conseguinte, o processo de avaliação.

Imersa nessa fase de crise do capitalismo com predomínio do capital financeiro, a avaliação em saúde tende a ser permeada pela lógica utilitarista, refletindo a ideologia do produtivismo, ao ser pautada pelas leis de mercado, em que a saúde de uma população é medida por meio do consumo de serviços e produtos médico-hospitalares, o que não significa, necessariamente, melhoria das condições dessa população.

Nesse panorama, vem se tornando essencial a construção de uma crítica ao processo produtivista. Para isso, dialoga-se com a literatura crítica, mediante uma interpretação marxista do processo atual, no sentido de repensar a política de saúde no âmbito do Sistema Único (SUS).

Conclui-se que o serviço em saúde deve se constituir em uma prática social, não se limitando a cumprir regras e normas, mas ser uma ferramenta para a consolidação da democracia, afirmação de direitos e empoderamento dos cidadãos.

A saúde pública no Brasil é um problema antigo que foi agravado pela pandemia de coronavírus. Nessa trilha de raciocínio, verificamos que a parcela mais rica da população tem acesso aos serviços de saúde privada se encontrando em posição mais confortável, enquanto a maioria depende do serviço público, enfrentando filas, hospitais lotados e de estrutura limitada, mas mesmo com todos os problemas de um sistema agonizante é a alternativa possível nos dias de hoje, com todos os percalços a situação seria infinitamente pior sem o sistema público.

\section{REFERÊNCIAS}

ARENDT, Hannah. Origens do Totalitarismo. São Paulo: Cia. das Letras, 1989.

BARCELlOS, Ana Paula. Curso de Direito Constitucional, 2. ed. São Paulo: Saraiva, 2019.

BOBBIO, Norberto. A era dos Direitos. Tradução Carlos Nelson Coutinho, 11. ed. Rio de Janeiro: Campus, 1992.

BRASIL. Constituição (1988). Constituição da República Federativa do Brasil. Brasília, DF: Senado Federal: Centro Gráfico, 1988.

BRASIL. Portaria $\boldsymbol{n}^{\boldsymbol{o}}$. 188-20-MS. Disponível em: https://www.in.gov.br/web/dou/-/portaria-n-188-de-3-de-fevereiro-de-2020-241408388. Acesso em: 30 ago. 2020.

BRASIL. Convenção $\mathbf{n}^{0} .102$ da Organização Internacional do Trabalho-OIT. Disponível em: https://www.ilo.org/brasilia/convencoes/WCMS_235192/lang--pt/index.htm. Acesso em: 30 ago. 2020. 
BRASIL. Decreto Legislativo $\boldsymbol{n}^{\boldsymbol{o}} \boldsymbol{6}$ de 2020. Disponível em: https://legislacao.presidencia. gov.br/atos $/$ ?tipo $=$ DLG\&numero $=6 \& a n o=2020 \&$ ato $=$ b1fAzZU5EMZpWT794. Acesso em: 30 ago. 2020.

CARVAlHO Fo . José dos Santos. Manual de Direito Administrativo, 25. ed. São Paulo: Editora Atlas S.A., 2012.

DELGADO, Guilherme; JACCOUD, Luciana. NOGUEIRA, Roberto Passos. Seguridade Social: Redefinindo O Alcance Da Cidadania. Disponível em: http://repositorio.ipea. gov.br/bitstream/11058/4347/1/bps_n17_vol01_seguridade_social .pdf. Acesso em: 18 ago. 2020.

PARANHOS, Vinícius Lucas. Efetividade dos provimentos judiciais na garantia do direito à saúde: Estudo sobre as decisões inaudita altera parte no fornecimento gratuito de medicamentos pelo Estado, v. 2, n. 1. Belo Horizonte: Meritum, 2007.

PEDREIRA. Ana Maria. A Responsabilidade do Estado por Omissão e o Princípio da Precaução e Prevenção como mecanismo para evitar o Dano. Porto Alegre: Núria Fabris Editora, 2016.

PIOVESAN, Flávia. Direitos humanos e justiça internacional: um estudo comparativo dos sistemas regionais europeu, interamericano e africano, 9. ed. rev. e atual. São Paulo: Saraiva Educação, 2019.

SCHWARTZ, Germano. Direito à saúde: Efetivação em uma perspectiva sistêmica. Porto Alegre: Livraria do Advogado, 2001.

\section{DADOS DA AUTORA}

\section{Raquel Torcani Carmona}

Advogada. Mestranda em Direitos Coletivos e Difusos pela Pontificia Universidade Católica de São Paulo-PUCSP. Especialista em Direito Educacional pela UNISAL. raquel@ semesp.org.br

Submetido em: 30-8-2020

Aceito em: 15-9-2020 